Mirko Cevec and Janez Plavec

\title{
Role of Loop Residues and Cations on the Formation and Stability of Dimeric DNA G-quadruplexes
}

Supporting Information

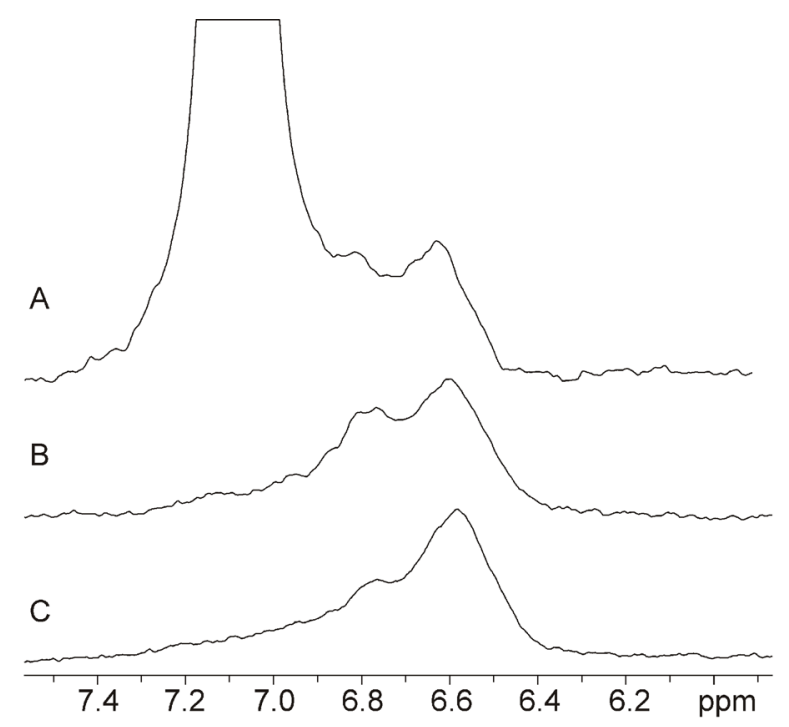

Figure S1. 1D ${ }^{15} \mathrm{~N}$-filtered ${ }^{1} \mathrm{H}$ NMR spectra of $1-3$ in the presence of ${ }^{15} \mathrm{NH}_{4} \mathrm{Cl}$ in $95 \% \mathrm{H}_{2} \mathrm{O}$ and $5 \%$ ${ }^{2} \mathrm{H}_{2} \mathrm{O}$ at $25{ }^{\circ} \mathrm{C}$. (A) $\mathrm{AB}(\mathbf{1})$ at $1.7 \mathrm{mM}$ concentration per strand in $40 \mathrm{mM}^{15} \mathrm{NH}_{4} \mathrm{Cl}$ and $\mathrm{pH}$ 5. (B) $\mathrm{C} 3$ (2) at $1.5 \mathrm{mM}$ concentration per strand in $5 \mathrm{mM}^{15} \mathrm{NH}_{4} \mathrm{Cl}$ and $\mathrm{pH}$ 7. (C) $\mathrm{H} \mathrm{(3)}$ at $2.0 \mathrm{mM}$ concentration per strand in $20 \mathrm{mM}^{15} \mathrm{NH}_{4} \mathrm{Cl}$ and $\mathrm{pH} 7$. 

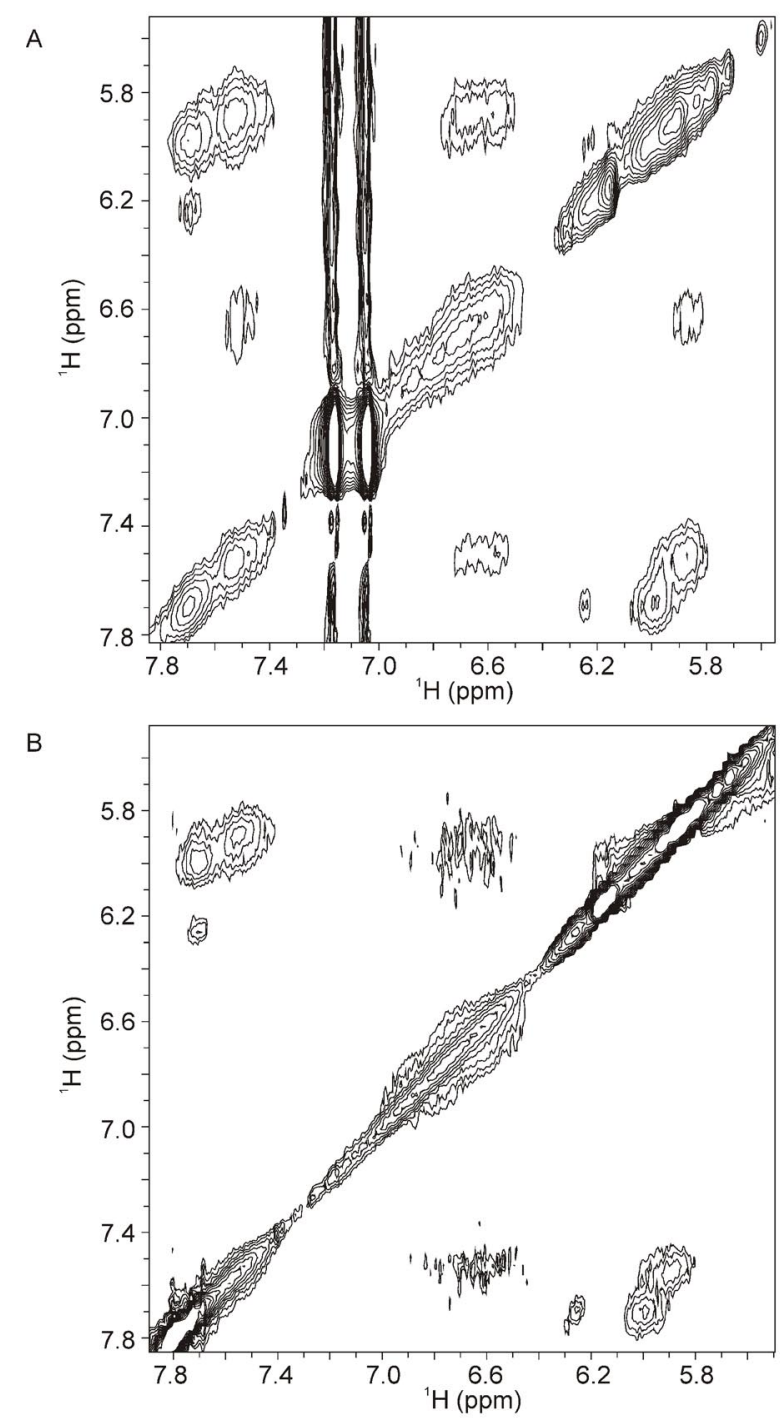

Figure S2. Aromatic-anomeric region of NOESY spectrum. (A) Oligonucleotide AB (1) in the presence of $40 \mathrm{mM}{ }^{15} \mathrm{NH}_{4} \mathrm{Cl}$ at pH 5 in $95 \% \mathrm{H}_{2} \mathrm{O}, 5 \%{ }^{2} \mathrm{H}_{2} \mathrm{O}$ at $25{ }^{\circ} \mathrm{C}$. (B) Oligonucleotide $\mathrm{C} 3$ (2) in the presence of $5 \mathrm{mM}{ }^{15} \mathrm{NH}_{4} \mathrm{Cl}$ at $\mathrm{pH} 7$ in $95 \% \mathrm{H}_{2} \mathrm{O}, 5 \%{ }^{2} \mathrm{H}_{2} \mathrm{O}$ at $25{ }^{\circ} \mathrm{C}$. 
Table S1. Translational diffusion constants $\left(D_{\mathrm{t}}\right)$ for 1-4.

\begin{tabular}{|c|c|c|}
\hline Oligo & $\begin{array}{l}\text { concentration of added ions } \\
\qquad(\mathrm{mM})\end{array}$ & $\begin{array}{c}D_{\mathrm{t}}^{a} \\
\left(10^{-6} \mathrm{~cm}^{2} \mathrm{~s}^{-1}\right)\end{array}$ \\
\hline \multirow{2}{*}{$\mathrm{AB}(\mathbf{1})$} & $10 \mathrm{mM} \mathrm{KCl}$ & 1.10 \\
\hline & $5 \mathrm{mM}^{15} \mathrm{NH}_{4} \mathrm{Cl}$ & 1.23 \\
\hline C3 (2) & $5 \mathrm{mM}^{15} \mathrm{NH}_{4} \mathrm{Cl}$ & 1.44 \\
\hline \multirow{2}{*}{$\mathrm{H}(\mathbf{3})$} & $10 \mathrm{mM} \mathrm{KCl}$ & 1.13 \\
\hline & $20 \mathrm{mM}^{15} \mathrm{NH}_{4} \mathrm{Cl}$ & 1.27 \\
\hline $\mathrm{T}(\mathbf{4})$ & $50 \mathrm{mM}^{15} \mathrm{NH}_{4} \mathrm{Cl}$ & 1.38 \\
\hline
\end{tabular}

